\title{
Characterization of soil lead
}

\section{by comparing sequential Gaussian simulation, simulated annealing simulation and kriging methods}

\author{
Yu-Pin Lin · Tsun-Kuo Chang · Tung-Po Teng
}

\begin{abstract}
This study attempted to characterize the spatial patterns of lead $(\mathrm{Pb})$ for further soil monitoring and remediation by comparing the sequential Gaussian simulation, simulated annealing techniques and ordinary kriging methods to delineate soil lead in a rice paddy field in the north of Changhua County, Taiwan. For reproducing the statistics of $\mathrm{Pb}$ and natural $\log \mathrm{Pb}(\ln (\mathrm{Pb}))$, simulation techniques yielded better results than ordinary kriging. Meanwhile, sequential Gaussian simulation and simulated annealing reproduced the spatial variation of the measured $\mathrm{Pb}$ and $\ln (\mathrm{Pb})$, as well as identified the global spatial continuity and discontinuity patterns. Furthermore, the simulated annealing method equaled the global measurement statistics and spatial patterns of $\mathrm{Pb}$ and $\ln (\mathrm{Pb})$ more so than sequential Gaussian simulation and kriging. Finally, the realizations generated by sequential Gaussian simulation displayed significantly higher local heterogeneity than those generated by simulated annealing. The realizations of simulated annealing simulation are consistent in presenting the spatial patterns of soil $\mathrm{Pb}$.
\end{abstract}

Received: 12 February 2001 / Accepted: 29 May 2001

Published online: 14 July 2001

(C) Springer-Verlag 2001

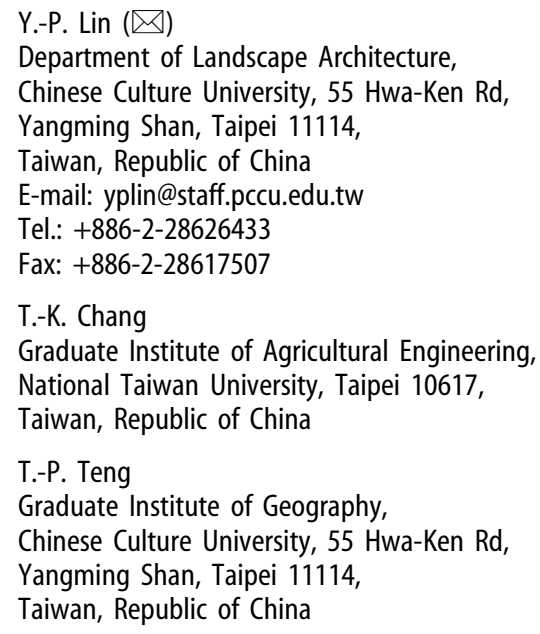

Keywords Sequential Gaussian simulation . Simulated annealing $\cdot$ Kriging $\cdot$ Soil heavy metal Spatial pattern and variability

\section{Introduction}

This study performed estimations based on ordinary kriging and simulations using sequential Gaussian simulation and simulated annealing techniques to produce maps and realizations of soil $\mathrm{Pb}$ and $\ln (\mathrm{Pb})$ within a case study. The descriptive statistics and spatial patterns of the simulated results are also discussed and compared. Finally, the spatial maps of soil $\mathrm{Pb}$ and $\ln (\mathrm{Pb})$ are displayed in geographic information systems (GIS) to elucidate the spatial patterns of soil $\mathrm{Pb}$.

Effective soil management must thoroughly consider soil properties and area delineation. Soil pollution data occasionally exhibit small-scale discontinuities or variable formations which may cause difficulties in delineating the characteristics of soil pollutants. Therefore, accurately identifying the spatial characteristics of pollutants ensures accurate risk assessment and remediation. In 1983, the Environmental Protection Administration (EPA) of Taiwan initiated a collaborative research program to determine the presence of $\mathrm{As}, \mathrm{Cd}, \mathrm{Cu}, \mathrm{Cr}, \mathrm{Hg}, \mathrm{Ni}, \mathrm{Pb}$ and $\mathrm{Zn}$ trace elements in the soil. The program also sought to detect additional soil properties, such as cation-exchange capacity and $\mathrm{pH}$ value. These studies sampled soils from 878 sites which were representative of essential agricultural areas across Taiwan.

Geostatistics can characterize and quantify spatial variability, perform rational interpolation, as well as estimate the variance of the interpolated values. Kriging, a geostatistical technique, is a linear interpolation procedure which provides a best linear unbiased estimator (BLUE) for quantities which vary in space. The procedure provides estimates at unsampled sites. Recently, kriging has been applied to analyze the spatial variability of pollutants. Notable examples include Zhang and others (1992), Samra and Gill (1993), Keck and others (1993), Litaor (1995), Zhang and others (1995), Steiger and others (1996), Couto and others (1997), White and others (1997), Wang (1998), Juang and Lee (1998), Wang and Zhang (1999), Chang and others (1999), Zhang and others (1999), and Lin and 
Chang (2000). However, kriging estimates display a lower variation than the investigated values, implying that the former do not preserve the high spatial variability and widely skewed distribution. Thus, lognormal kriging was developed to account for the frequently skewed distribution of investigated data (Roth 1998). This technique transforms the data into a lognormal formation prior to kriging estimation. Relevant works on involving this technique include Rendu (1979), Journel (1980), Dowd (1982), Rivoirard (1990), Christensen (1997), Fabbri (1997), and Roth (1998).

Stochastic conditional simulation techniques, such as sequential Gaussian simulation and simulated annealing, can be applied to generate multiple realizations, including an error component, absent from classical interpolation techniques. The mentioned simulation techniques generate a set of values with a specified mean and covariance, and also reproduce measured data at several locations. However, these realizations match the similar sample statistics and the conditioning data provide a visual and quantitative measure of spatial uncertainty (Goovaerts 1996). For instance, along with simulated values, measurements herein can be used to analyze the spatial distribution of the variable in question. Conditional simulation techniques have been applied in many fields. Notable examples include Varljen and Shafer (1991), Rouhani and others (1995), Eggleston and others (1996), Mowrer (1997), Sterk and Stein (1997), and Kentwell and others (1999). Furthermore, these techniques have been recently applied to characterize the spatial variability of pollutants. Istok and Rautman (1996) used sequential Gaussian simulation to characterize nitrate and Dacthal contamination in groundwater studies. Meanwhile, Wang and Zhang (1999) applied a turning band method to re- produce multiple heavy-metal realizations. Finally, Lin and Chang (2000) applied sequential Gaussian simulation to generate multiple realizations and identify the spatial patterns of soil zinc.

\section{Materials and methods}

\section{Data}

Figure 1 displays the study area at a rice paddy field in the north of Changhua County, Taiwan. It shows the irrigation-drainage ditch system surrounded by industrial plants whose wastewater was possibly discharged into irrigation ditches and used for agricultural purposes. The data obtained in this study were described by the EPA of Taiwan. This work includes 194 sampling locations (Fig. 2) in the simulation of the soil $\mathrm{Pb}$ spatial distribution. Furthermore, these measurements were collected during the period 1983 through to 1986. Samples were taken from geographically distributed sites at target intervals of 100 and $50 \mathrm{~m}$ in a network formation. Meanwhile, topsoil samples were taken at depths of $0-15 \mathrm{~cm}$. The soil $\mathrm{Pb}$ classified by ROC EPA as the first, second, third, fourth, and fifth classes are $<1,1-15,16-120,>120 \mathrm{mg} / \mathrm{kg}$, respectively. The fourth and fifth soil classes required intensive monitoring and remediation.

Figure 2 presents the spatial maps of $\mathrm{Pb}$ and $\ln (\mathrm{Pb})$ measurements. The measured values of 129 sampling points, that is, $66.5 \%$ of the total sampling points, were classed in the third class. Sixty-five sampling points, that is, $33.5 \%$ of total sampling points, were classed in the fourth class. Figure 3 displays the histograms of $\mathrm{Pb}$ and $\ln (\mathrm{Pb})$. Meanwhile, Table 1 summarizes the statistics of

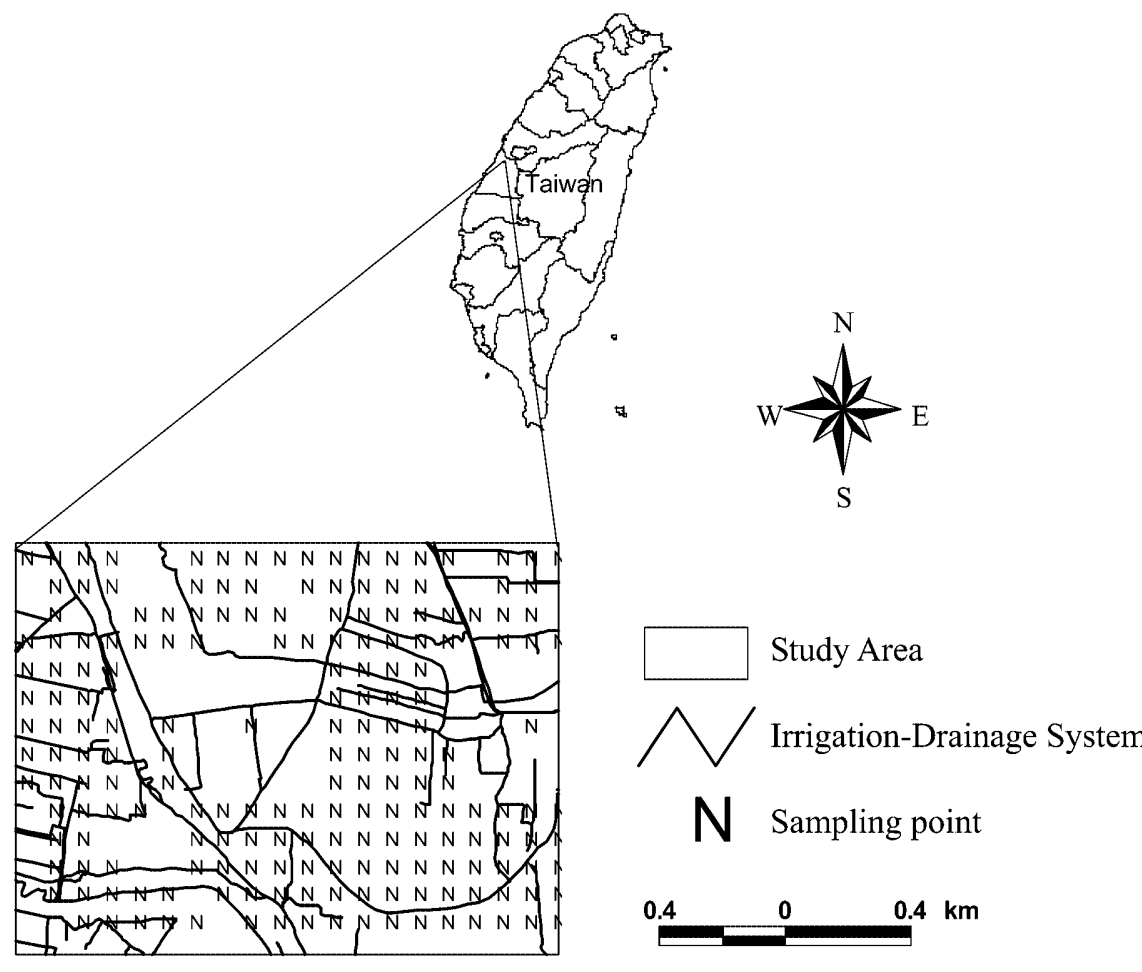

Fig. 1

Study area 


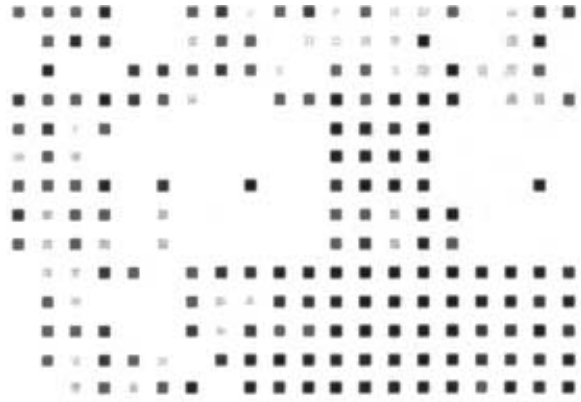

(a)

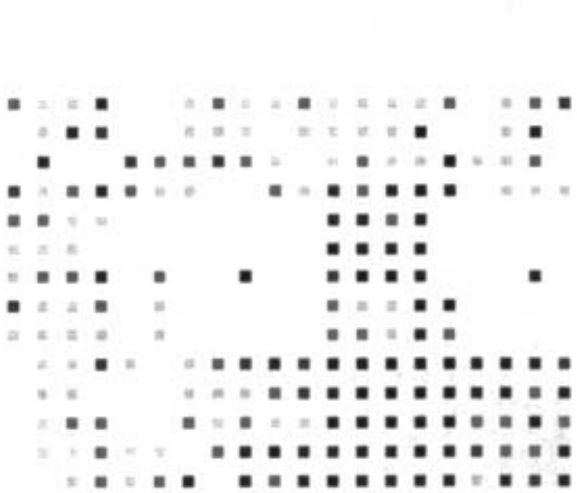

(b)

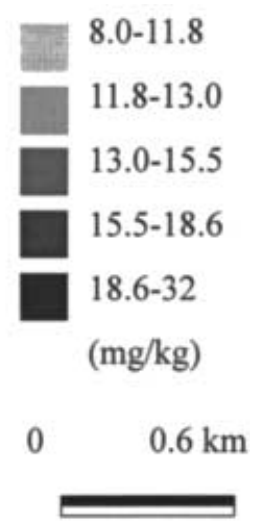

$2.0-2.5$
$2.5-2.6$
$2.6-2.7$
$2.7-2.9$
$2.9-4.0$

$\ln (\mathrm{mg} / \mathrm{kg})$

Fig. 2a-b

Sampling points

the investigated data. The normal distributions of $\mathrm{Pb}$ and $\ln (\mathrm{Pb})$ data were also tested using the Kolmogorov-Smirnov test (Table 1). Based upon the 2-tailed test, $\mathrm{Pb}$ and $\ln (\mathrm{Pb})$ data normal distribution was not evident at the 0.01 significance level. According to Figs. 2 and 3 as well as Table $1, \mathrm{~Pb}$ and $\ln (\mathrm{Pb})$ data also confirmed non-normal distributions. Furthermore, the 2-tailed KolmogorovSmirnov test indicated normal distribution of the $\ln (\mathrm{Pb})$ data at the 0.05 significance level.

\section{Ordinary kriging}

Within a statistical framework, geostatistics provides a variogram of data, including spatial and temporal covariance functions. As spatial or temporal structures, these variogram models are defined based upon the correlation between any two points separated by either spatial or temporal distances.

Ordinary kriging, as applied within moving data neighborhoods, is a non-stationary algorithm which corresponds to a non-stationary random function model with varying mean but stationary covariance (Deutsch and
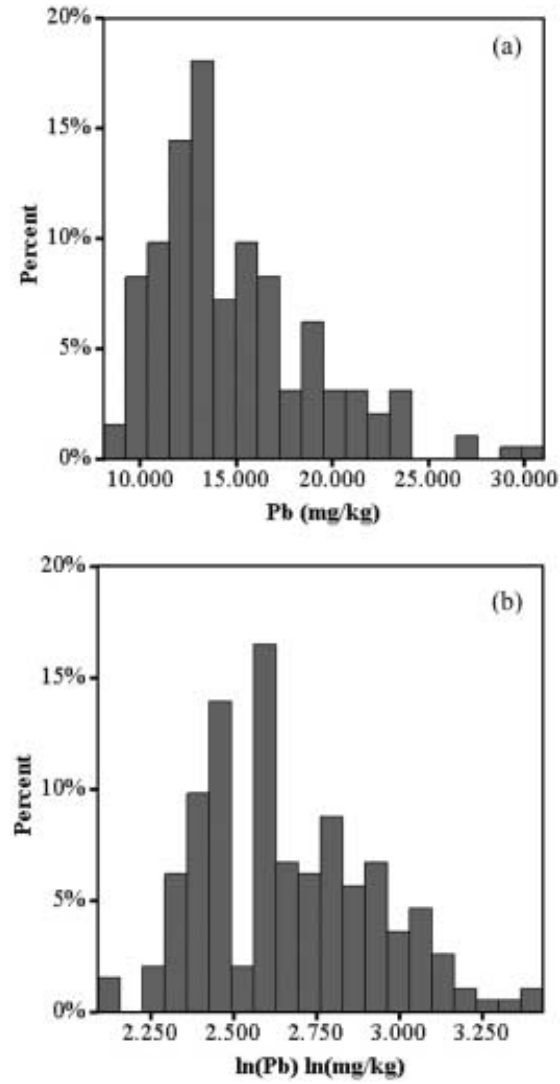

Fig. 3a-b

Histograms of $\mathbf{a} \mathrm{Pb} ; \mathbf{b} \ln (\mathrm{Pb})$

Journel 1992). Kriging estimates are calculated as weighted sums of the adjacent sampled concentrations. These weights depend on the exhibited correlation structure. That is, if data appear to be highly continuous in space, the points closer to those estimated receive higher weights than those farther away. These weights are selected based upon a minimization of the estimation variance. In this framework, kriging estimates are considered the most accurate among all linear estimators (i.e., best linear unbiased estimator). Therefore, at an unsampled location and for a given variogram, a kriging estimate is simply an optimally weighted average of the surrounding sampled data (Cressie 1990).

\section{Sequential Gaussian simulation}

Sequential Gaussian simulation assumes a Gaussian random field, thus, the conditional cumulative density function (cdf) is completely characterized by the mean value and covariance (Fredericks and Newman 1998). In the

Table 1

Descriptive statistics of investigated data of $\mathrm{Pb}$ and $\ln (\mathrm{Pb}) . S D$ Standard deviation. $K-S Z$ Kolmogorov-Smirnov Z. $\mathrm{Pb}$ unit in mg/kg, $\ln (\mathrm{Pb})$ unit in $\ln (\mathrm{mg} / \mathrm{kg})$

\begin{tabular}{|c|c|c|c|c|c|c|c|c|}
\hline Variable & Mean & Median & $\mathrm{SD}$ & Min & Max & 25 th & 75th & K-S Z \\
\hline $\mathrm{Pb}$ & 14.826 & 13.685 & 4.118 & 8.100 & 31.000 & 12.000 & 17.000 & 2.112 \\
\hline $\operatorname{Ln}(\mathrm{Pb})$ & 2.663 & 2.616 & 0.260 & 2.100 & 3.400 & 2.485 & 2.833 & 1.487 \\
\hline
\end{tabular}


sequential Gaussian simulation process, simulation is conducted upon the Gaussian transformation of the available measurements, so that each simulated value is conditional on the original data and all previously simulated values (Deutsch and Journel 1992; Rouhani and others 1995). A simulated value at one location is randomly selected from the normal distribution function defined by the kriging mean and variance based on neighborhood values. Finally, the simulated normal values are back transformed into simulated values for an original variable. The simulated value at the new randomly visited point value is dependent upon both the original data and previously simulated values. This process is repeated until all points are simulated.

\section{Simulation by simulated annealing}

The annealing algorithm perturbs the image by simulating thermal perturbation (Deutsch and Cockerham 1994). However, for generating an initial field by drawing random values from a given histogram, simulated annealing is an optimization technique. Swapping the values in pairs of grid nodes which do not include a conditioning datum sequentially modifies this initial field. A swap is allowed if the objective function is lower (Deutsch and Journel 1992). The objective function is defined as an average squared difference between the experimental and given variograms. A temperature function (the Boltzman distribution) within a simulated annealing procedure controls the reduction speed of the optimization function by allowing some switches to increase the optimization function (Deutsch and Journel 1992; Eggleston and others 1996). The parameter of the temperature function, $(\mathrm{t})$, is named as the temperature within the annealing procedure. However, higher temperature increases the probability that an unfavorable swap will be accepted (Deutsch and Journel 1992).

In this study, the variogram models of $\mathrm{Pb}$ and $\ln (\mathrm{Pb})$ were also fitted within GS+ (Gamma Design 1995). Ordinary kriging, sequential Gaussian simulation and simulated annealing for $\mathrm{Pb}$ and $\ln (\mathrm{Pb})$ data were performed by OKB2DM (ordinary kriging two-dimensional), SGSIM (sequential Gaussian simulation) and SASIM (simulated annealing simulation) in GSLIB (Geostatistical Software Library; Deutsch and Journel 1992). These simulations (sgs1, 2 and 3, and sas1, 2 and 3) and estimates from the Gaussian sequential, simulation simulated annealing and kriging were performed in a square 38 column with a 28row grid consisting of $1,06450 \times 50 \mathrm{~m}$ cells. The correlations between soil $\mathrm{Pb}$ estimations and simulations were also calculated and discussed. To identify the spatial patterns and classes of soil lead at this site, the results were transferred into Arcview 3.0 (ESRI 1998).

\section{Results and discussion}

\section{Variography}

Experimental variograms were calculated for $\mathrm{Pb}$ and $\ln (\mathrm{Pb})$ at the same active lag and lag interval. A relatively consistent set of best-fit models with minimum RSS (model reduced sum of squares) and maximum $\mathrm{r}^{2}$ values were generated by least squares model fitting of these variograms. Table 2 presents the best-fit models for $\mathrm{Pb}$ and $\ln (\mathrm{Pb})$. An exponential model with a nugget effect $=6.300(\mathrm{mg} / \mathrm{kg})^{2}$, a sill $=12.200(\mathrm{mg} / \mathrm{kg})^{2}$ and a ran$\mathrm{ge}=850 \mathrm{~m}$ was the best-fit model for $\mathrm{Pb}$ data. Meanwhile, a spherical model with a nugget effect $=0.454$, a sill $=0.446$ and a range $=845 \mathrm{~m}$ was the variogram of normalized $\mathrm{Pb}$. In both $\mathrm{Pb}$ and normalized $\mathrm{Pb}$ data, a spatial structure was exhibited below $850 \mathrm{~m}$. The best-fit model for $\ln (\mathrm{Pb})$ data was a spherical model with a nugget effect $=0.031(\ln (\mathrm{mg} /$ $\mathrm{kg}))^{2}$, a sill $=0.045(\ln (\mathrm{mg} / \mathrm{kg}))^{2}$ and a range $=1,065.0 \mathrm{~m}$. Variography results indicated that the variogram models of $\mathrm{Pb}$ having a high nugget effect display a higher smallscale variation or measurement error.

\section{Statistical comparative estimation and simulation}

The ordinary kriging estimates and simulations were based on the above variogram models and the 194 soil $\mathrm{Pb}$ and $\ln (\mathrm{Pb})$ observations. Tables 3 and 4 summarize the descriptive statistics related to ordinary kriging, Gaussian sequential simulation and simulated annealing results. This comparison reveals that conditional simulations, including Gaussian sequential simulation and simulated annealing, produce the empirical data for $\mathrm{Pb}$, excluding the mean value, better than kriging.

The median values $(13.669-13.761 \mathrm{mg} / \mathrm{kg}$ ) of the $\mathrm{Pb}$ simulations using simulated annealing were almost identical to that $(13.685 \mathrm{mg} / \mathrm{kg}$ ) of the measured $\mathrm{Pb}$ data (Tables 1 and 3). Moreover, the 25th and 75th percentiles from simulated annealing were identical to those of the empirical $\mathrm{Pb}$ data (Tables 1 and 3). Tables 1 and 3 also indicate that the 25th and 75th percentiles of the simulations by Gaussian sequential simulation were almost identical to those of the empirical $\mathrm{Pb}$ data. Meanwhile, the standard deviation values (3.919-4.122 and 3.770-4.182 $\mathrm{mg} / \mathrm{kg}$ ) of the results from Gaussian sequential simulation and sim-

Table 2

Variogram model of $\mathrm{Pb}, \ln (\mathrm{Pb})$ and normalized $\mathrm{Pb}$ data

\begin{tabular}{|c|c|c|c|c|}
\hline Heavy metal & Model & $\begin{array}{l}\text { Nugget effect }\left(\mathrm{C}_{0}\right) \\
(\mathrm{mg} / \mathrm{kg})^{2}\end{array}$ & $\begin{array}{l}\text { Sill }(\mathrm{C}) \\
(\mathrm{mg} / \mathrm{kg})^{2}\end{array}$ & $\begin{array}{l}\text { Range (a) } \\
(\mathrm{m})\end{array}$ \\
\hline $\mathrm{Pb}$ & $\mathrm{C}_{0}+\mathrm{C}(\exp (-\mathrm{h} / \mathrm{a}))$ & 6.300 & 12.200 & 850 \\
\hline Normal $\mathrm{Pb}$ & $\mathrm{C}_{0}+\mathrm{C}(1.5(-\mathrm{h} / \mathrm{a})-0.5(-\mathrm{h} / \mathrm{a}))$ & 0.454 & 0.446 & 845 \\
\hline $\operatorname{Ln}(\mathrm{Pb})$ & $\mathrm{C}_{0}+\mathrm{C}(1.5(-\mathrm{h} / \mathrm{a})-0.5(-\mathrm{h} / \mathrm{a}))$ & 0.053 & 0.045 & 1,065 \\
\hline
\end{tabular}


Table 3

Descriptive statistics of kriging estimates and simulations of $\mathrm{Pb} . S D$ Standard deviation. Units in $\mathrm{mg} / \mathrm{kg}$

\begin{tabular}{|c|c|c|c|c|c|c|c|}
\hline Variable & Mean & Median & SD & Min. & Max. & 25th Percent. & 75th Percent. \\
\hline SAS 1 & 14.775 & 13.693 & 3.919 & 8.100 & 31.020 & 12.000 & 17.000 \\
\hline SAS 3 & 14.847 & 13.669 & 4.122 & 8.100 & 31.020 & 12.000 & 17.000 \\
\hline SGS 1 & 14.702 & 13.684 & 3.770 & 8.100 & 31.020 & 12.000 & 16.750 \\
\hline SGS 2 & 14.548 & 13.414 & 4.036 & 8.100 & 31.020 & 12.000 & 16.860 \\
\hline SGS 3 & 15.034 & 14.000 & 4.182 & 8.100 & 31.020 & 12.000 & 17.000 \\
\hline
\end{tabular}

Table 4

Descriptive statistics of kriging estimates and simulations of $\ln (\mathrm{Pb}) . S D$ Standard deviation. Units in $\ln (\mathrm{mg} / \mathrm{kg})$

\begin{tabular}{|c|c|c|c|c|c|c|c|}
\hline Variable & Mean & Median & SD & Min. & Max. & 25th Percent. & 75th Percent. \\
\hline SAS 1 & 2.663 & 2.617 & 0.254 & 2.092 & 3.435 & 2.485 & 2.833 \\
\hline SAS 3 & 2.662 & 2.622 & 0.255 & 2.092 & 3.435 & 2.485 & 2.833 \\
\hline SGS 1 & 2.659 & 2.616 & 0.238 & 2.092 & 3.435 & 2.485 & 2.818 \\
\hline SGS 2 & 2.643 & 2.485 & 0.259 & 2.092 & 3.435 & 2.485 & 2.825 \\
\hline SGS 3 & 2.676 & 2.485 & 0.271 & 2.092 & 4.817 & 2.485 & 2.833 \\
\hline
\end{tabular}

ulated annealing also approached the empirical $\mathrm{Pb}$ data value $(4.118 \mathrm{mg} / \mathrm{kg})$. Based upon the above class definition of EPA in Taiwan, there were $68.9 \%$ of kriged estimates in the third class. The remaining belonged to the fourth class. The third classes of sequential Gaussian simulations percentages of the 1,064 points in each simulation were 69.3 , 69.3 , and $65.4 \%$. The third classes of simulated annealing percentages of the 1,064 points in each simulation were $66.9,66.0$, and $66.0 \%$.

However, the results illustrate that both the Gaussian sequential simulation and simulated annealing reproduced the standard deviation of measured $\mathrm{Pb}$ better than kriging. Moreover, the above results also indicated that the ordinary kriging process might not preserve the variability and skewness of the investigated process. However, Gaussian sequential simulation and simulated annealing reproduced empirical $\mathrm{Pb}$ statistics and provided results which matched the global statistics of $\mathrm{Pb}$ measurement better than sequential Gaussian simulation and kriging.

Table 4 summarizes the statistics of kriging and $\ln (\mathrm{Pb})$ simulation results and revealed that conditional simulations, including Gaussian sequential simulation and simulated annealing, produced empirical data which related to the $\ln (\mathrm{Pb})$ better than kriging (Tables 1 and 4). The mean values $(2.652-2.663 \ln (\mathrm{mg} / \mathrm{kg}))$ of simulated annealing simulations were extremely close to the mean value $(2.663 \ln (\mathrm{mg} / \mathrm{kg}))$ of $\ln (\mathrm{Pb})$ data. Furthermore, the median values $(2.614-2.622 \ln (\mathrm{mg} / \mathrm{kg}))$ of the $\ln (\mathrm{Pb})$ simulated annealing were almost identical to those $(2.616 \ln (\mathrm{mg} / \mathrm{kg}))$ of the $\ln (\mathrm{Pb})$ data (Tables 1 and 4). Additionally, the 25th and 75th percentiles of the simulated annealing results were identical to those of the $\ln (\mathrm{Pb})$ data. Tables 1 and 3 also reveal that the 25th and 75th percentiles of the Gaussian sequential simulation results were almost identical to those of the $\ln (\mathrm{Pb})$ data. Meanwhile, the standard deviation values $(0.254-0.256 \ln (\mathrm{mg} / \mathrm{kg})$ and $0.238-$
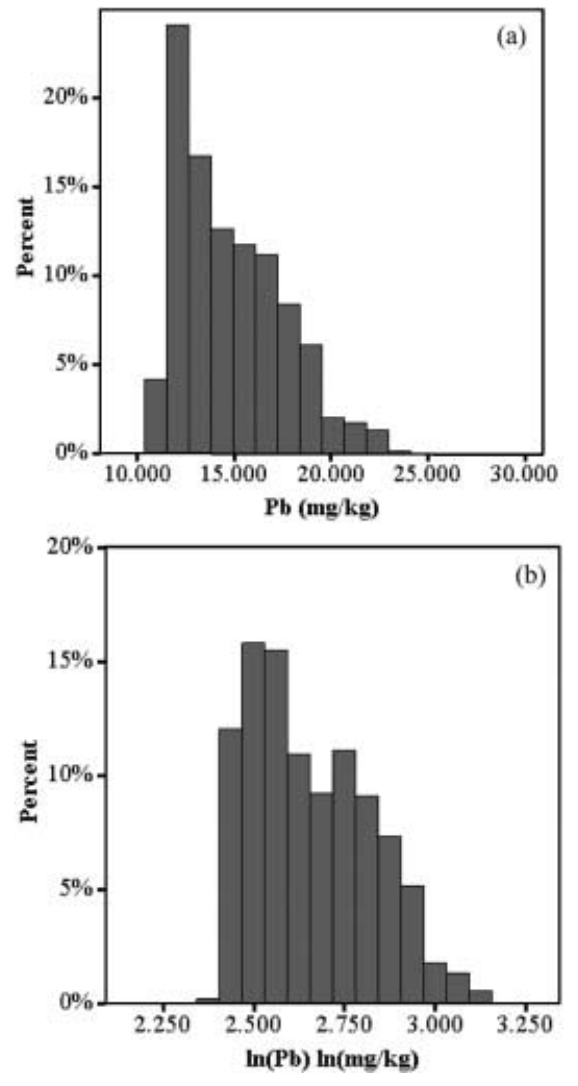

Fig. 4a-b

Histograms of $\mathbf{a} \mathrm{Pb}$ kriging estimates; $\mathbf{b} \ln (\mathrm{Pb})$ kriging estimates

$0.271 \ln (\mathrm{mg} / \mathrm{kg}))$ of Gaussian sequential and simulated annealing were close to that $(0.260 \ln (\mathrm{mg} / \mathrm{kg}))$ of $\ln (\mathrm{Pb})$ data. However, simulations which included Gaussian sequential simulation and simulated annealing reproduced the standard deviation of $\ln (\mathrm{Pb})$ better than kriging. 

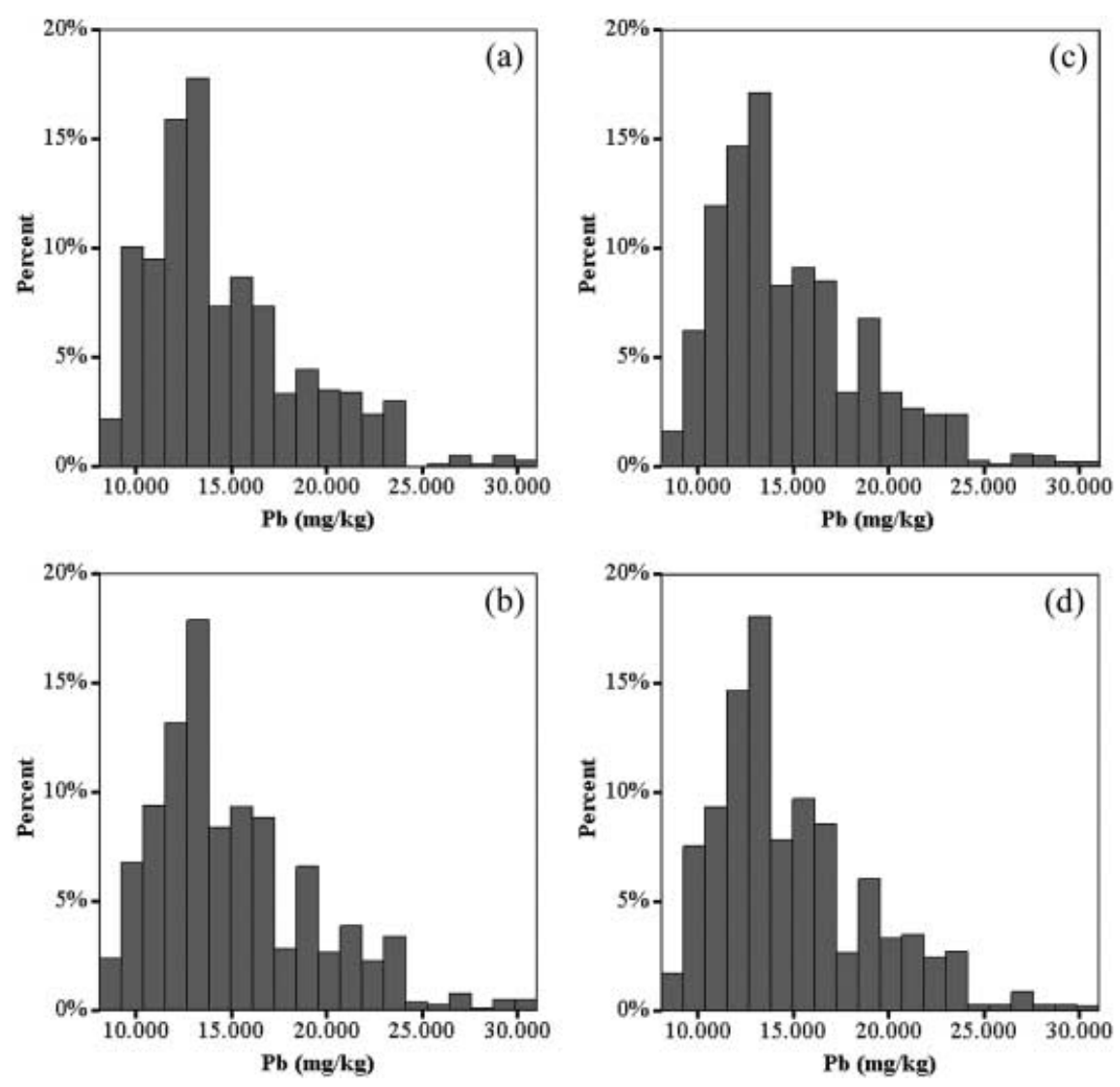

Fig. 5a-d

Histograms of $\mathrm{Pb}$ of a sgs2; b sgs 3 ; c sas1; d sas2
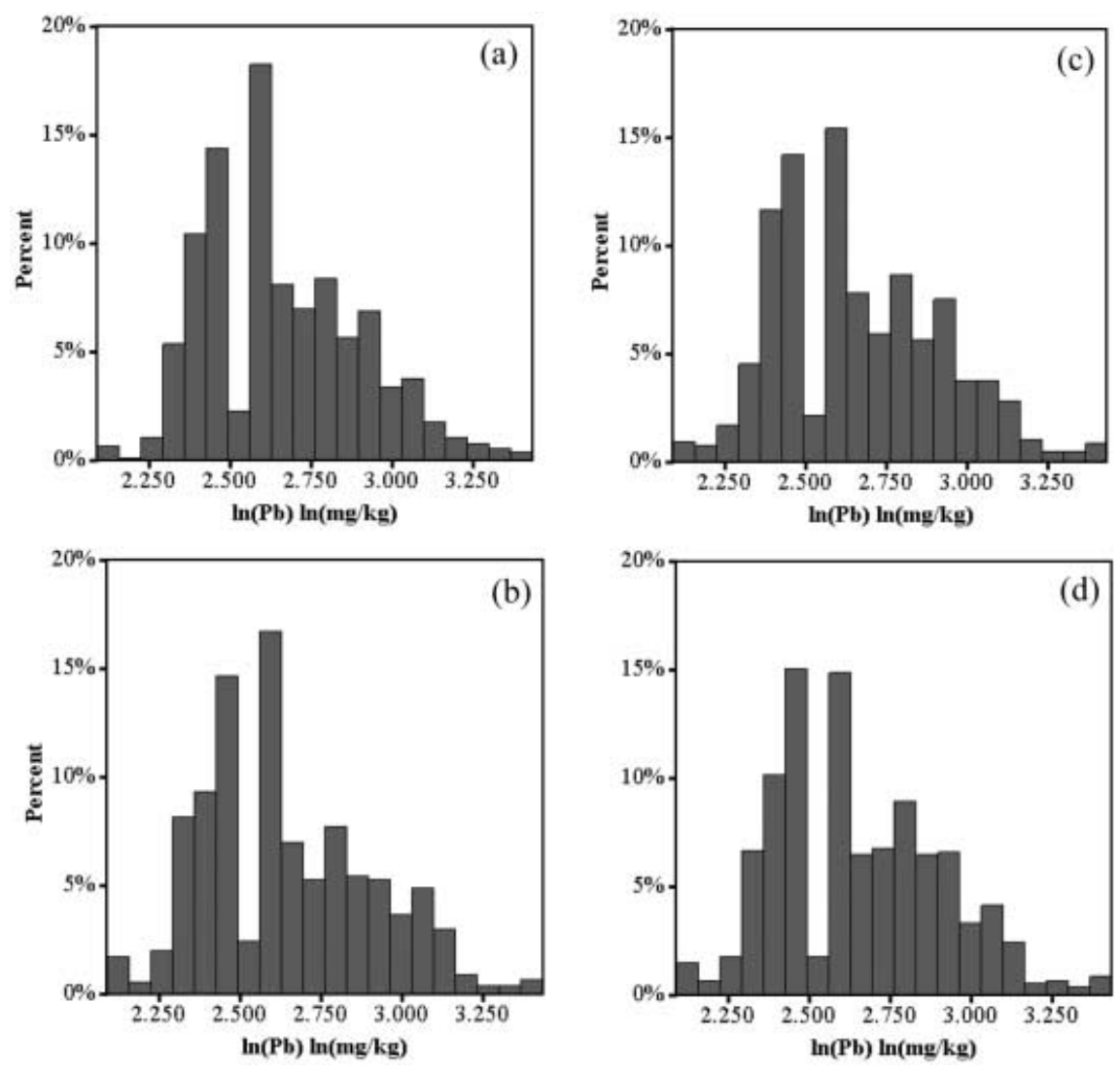

Fig. 6a-d

Histograms of $\ln (\mathrm{Pb})$ of a sgs 1 ; b sgs2; c sas 1 ; d sas2 
Table 5

Correlation coefficients between kriging estimates and realization of $\mathrm{Pb}$. ${ }^{* *}$ Correlation is significant at the 0.01 level (two-tailed). OK Ordinary kriging; SGS simulated Gaussian simulation; $S A S$ simulated annealing simulation

\begin{tabular}{|c|c|c|c|c|c|c|c|}
\hline & $\mathrm{OK}$ & SGS1 & SGS2 & SGS3 & SAS1 & SAS2 & SAS3 \\
\hline $\mathrm{OK}$ & 1.000 & $0.488^{* *}$ & $0.556^{* *}$ & $0.586^{* *}$ & $0.719^{\star *}$ & $0.729^{\star *}$ & $0.733^{\star *}$ \\
\hline SGS 1 & $0.488^{* *}$ & 1.000 & $0.334^{* *}$ & $0.358^{* *}$ & $0.397^{* *}$ & $0.369^{* *}$ & $0.400^{* *}$ \\
\hline SGS 2 & $0.556^{* *}$ & $0.334^{* *}$ & 1.000 & $0.433^{\star *}$ & $0.455^{\star *}$ & $0.448^{\star *}$ & $0.487^{\star *}$ \\
\hline SGS 3 & $0.586^{* *}$ & $0.358^{* *}$ & $0.433^{* *}$ & 1.000 & $0.445^{\star *}$ & $0.443^{\star *}$ & $0.501^{\star *}$ \\
\hline SAS 1 & $0.719^{* *}$ & $0.397^{\star *}$ & $0.455^{\star *}$ & $0.445^{\star *}$ & $1.000^{* *}$ & $0.620^{\star *}$ & $0.607^{\star \star}$ \\
\hline SAS 2 & $0.729^{\star *}$ & $0.369^{\star *}$ & $0.448^{* *}$ & $0.443^{* *}$ & $0.620^{* *}$ & 1.000 & $0.636^{\star *}$ \\
\hline SAS 3 & $0.733^{* *}$ & $0.400^{* *}$ & $0.487^{* *}$ & $0.501^{* *}$ & $0.607^{* *}$ & $0.636^{* *}$ & 1.000 \\
\hline
\end{tabular}

Table 6

Correlation coefficients between kriging estimates and realization of $\ln (\mathrm{Pb}) .{ }^{*}$ Correlation is significant at the 0.01 level $(2$-tailed). OK Ordinary kriging; SGS simulated Gaussian simulation; $S A S$ simulated annealing simulation

\begin{tabular}{|c|c|c|c|c|c|c|c|}
\hline & $\operatorname{lnOK}$ & SGS1 & SGS2 & SGS3 & SAS1 & SAS2 & SAS3 \\
\hline $\operatorname{lnOK}$ & 1.000 & $0.488^{\star *}$ & $0.550^{* *}$ & $0.582^{* *}$ & $0.615^{* *}$ & $0.610^{* *}$ & $0.590^{* *}$ \\
\hline SGS 1 & $0.488^{\star *}$ & 1.000 & $0.337^{\star *}$ & $0.361^{\star *}$ & $0.339^{\star *}$ & $0.374^{\star *}$ & $0.371^{\star *}$ \\
\hline SGS 2 & $0.550^{* *}$ & $0.337^{\star *}$ & 1.000 & $0.431^{* *}$ & $0.437^{* *}$ & $0.392^{* *}$ & $0.389^{* *}$ \\
\hline SGS 3 & $0.582^{\star *}$ & $0.361^{\star \star}$ & $0.431^{* *}$ & 1.000 & $0.442^{\star *}$ & $0.371^{\star *}$ & $0.411^{\star *}$ \\
\hline SAS 1 & $0.615^{\star *}$ & $0.339^{* *}$ & $0.437^{* *}$ & $0.442^{\star *}$ & 1.000 & $0.507^{* *}$ & $0.469^{* *}$ \\
\hline SAS 2 & $0.610^{* *}$ & $0.374^{\star *}$ & $0.392^{* *}$ & $0.371^{* *}$ & $0.507^{* *}$ & 1.000 & $0.472^{* *}$ \\
\hline SAS 3 & $0.590^{\star *}$ & $0.371^{\star *}$ & $0.389^{* *}$ & $0.411^{* *}$ & $0.469^{* *}$ & $0.472^{\star *}$ & 1.000 \\
\hline
\end{tabular}

Based upon the definition of EPA classification in natural log transform, $66.4 \%$ of the natural log kriged estimates were within the third class $(0-2.773 \ln (\mathrm{mg} / \mathrm{kg}))$. The remaining were the fourth class $(2.773-4.787 \ln (\mathrm{mg} / \mathrm{kg}))$. The third class percentages of sequential Gaussian simulations were $69.3,69.3$, and $65.3 \%$. The third classes of simulated annealing percentages were $65.3,67.2$, and $66.5 \%$.

Also, minimizing a kriging prediction error variance involves smoothing the actual variability. However, Gaussian sequential simulation and simulated annealing reproduce the statistics for empirical $\mathrm{Pb}$ and $\ln (\mathrm{Pb})$ data. Finally, the simulated annealing method had a much better fit to global statistics of $\mathrm{Pb}$ and $\ln (\mathrm{Pb})$ than sequential Gaussian simulation and kriging.

Figures 4, 5 and 6 display the estimates and simulations histograms. According to these figures, the simulation method closely matches the right- and left-hand tails of the distribution for heavy metals, which contain high and low concentration values. However, the above figures further indicate that the Gaussian sequential simulation and simulated annealing reproduce the distribution of $\mathrm{Pb}$ and $\ln (\mathrm{Pb})$ better than kriging. Furthermore, kriging produces smoothed data which cannot capture the distributions or spatial changes of the $\mathrm{Pb}$ and $\ln (\mathrm{Pb})$ data.

\section{Correlation of estimation and simulation}

In this study, to identify the correlation between estimation and simulation, particularly the latter, Pearson and Spearman correlation coefficients were calculated for 1,064 pairs. Table 5 , which lists the coefficients, reveals significant linear correlation at the 0.01 probability level. The correlation coefficients between kriging estimates and each realization range from 0.488 to 0.733 (Table 5). These results imply that the kriging estimates and simulated realizations have a common origin and exhibit a similar spatial pattern of soil $\mathrm{Pb}$. According to the 2-tailed test, the correlation coefficients among the realizations of all simulations are significant at the 0.01 probability level (Table 5). These coefficients range from 0.334 to 0.636 .

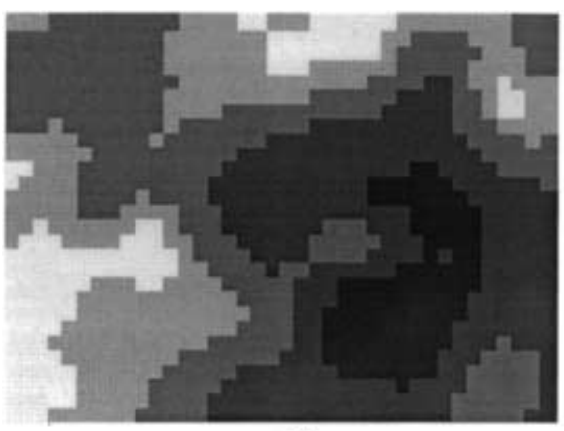

$8.0-11.8$

$11.8-13.0$

$13.0-15.5$

$15.5-18.6$

$18.6-32$

$(\mathrm{mg} / \mathrm{kg})$

(a)

$0 \quad 0.6 \mathrm{~km}$

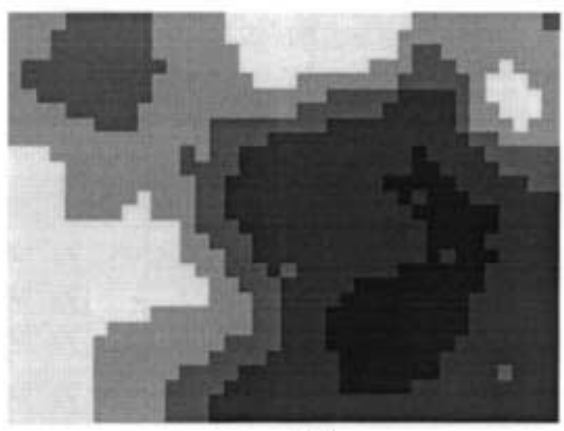

(b)

$2.0-2.5$

$2.5-2.6$

2.6-2.7

2.7-2.9

$2.9-40$

$\ln (\mathrm{mg} / \mathrm{kg})$
Fig. 7a-b

Kriged map of $\mathbf{a} \mathrm{Pb} ; \mathbf{b} \ln (\mathrm{Pb})$ 
Specifically, the simulated annealing coefficients range from 0.607 to 0.636 . Moreover, the correlation coefficients among the realizations of simulated annealing simulation are strongly significant at the 0.01 probability level, according to the 2-tailed test shown in Table 5. These results imply that the realizations of simulated annealing simulation are consistent in presenting the spatial patterns of soil $\mathrm{Pb}$.

Table 6 lists the Pearson correlation coefficients among estimated results and simulated realizations of $\ln (\mathrm{Pb})$. The correlation coefficients between kriging estimates and each realization ranged from 0.488 to 0.615 . However, there is significant linear correlation at the 0.01 probability level (Table 6). These results imply that the kriging estimates and simulated realizations also have a common origin and exhibit a similar spatial pattern of $\ln (\mathrm{Pb})$. Table 6 reveals that under the same conditions of $\mathrm{Pb}, \ln (\mathrm{Pb})$ displays the same correlation coefficients. These coefficients range from 0.337 to 0.507 . The simulated annealing coefficients ranged from 0.469 to 0.507 . Moreover, the correlation coefficients among the realizations of simulated annealing simulation are strongly significant at the 0.01 probability level, according to the two-tailed test shown in Table 6.

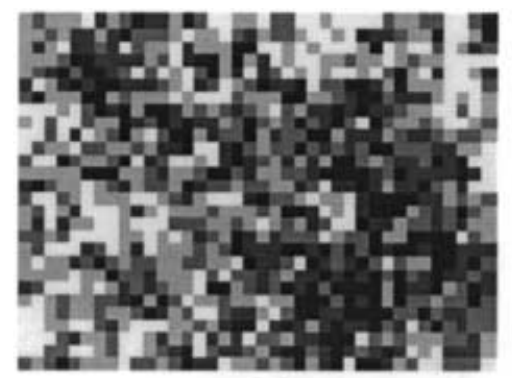

(a)

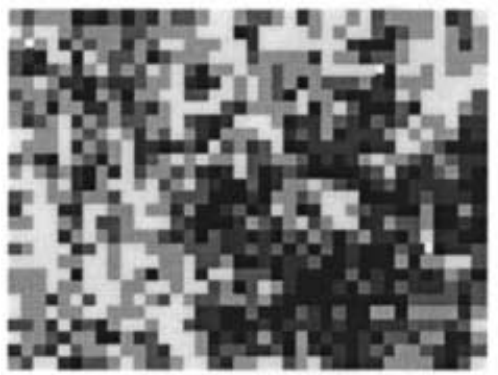

(b)
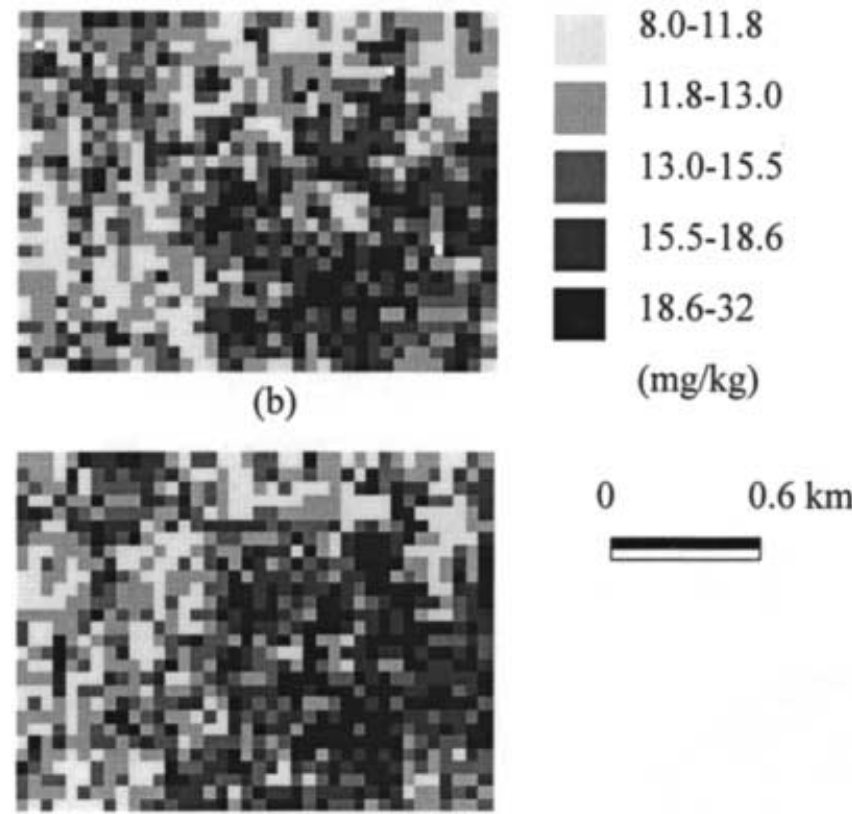

(C)

Fig. 8a-c

$\mathrm{Pb}$ simulated maps of a sgs1; b sgs2; c sgs3
These results imply that the realizations of simulated annealing simulation are consistent in presenting the spatial patterns of soil $\ln (\mathrm{Pb})$.

\section{Spatial pattern of estimation and simulations}

Figures 7, 8, 9, 10 and 11 indicate that estimates and simulations were mapped using Arcview 3.0a. Figure 7 presents the kriged map of $\mathrm{Pb}$ and $\ln (\mathrm{Pb})$, in which the high concentration areas were located in the southeast of the investigation area. The ordinary kriging estimate maps of Fig. 7 confirmed that kriging tended to smooth extreme values of the empirical $\mathrm{Pb}$ and $\ln (\mathrm{Pb})$ data set. Although indicating the spatial patterns of these soil heavy metals, kriging results might overestimate the size of high and low concentration areas of soil heavy metals, and underestimate areas with extremely high and low concentrations of $\mathrm{Pb}$ and $\ln (\mathrm{Pb})$.

Figures 8, 9, 10 and 11 display the simulation maps of $\mathrm{Pb}$ and $\ln (\mathrm{Pb})$. Similar to the kriging map, Figs. 8 and 9 also display a high continuity area with high $\mathrm{Pb}$ concentration in the southeast. Similar to the $\ln (\mathrm{Pb})$, the kriging and simulated maps of $\mathrm{Pb}$, Figs. 10 and 11 also display a high continuity area with high $\ln (\mathrm{Pb})$ concentration in the

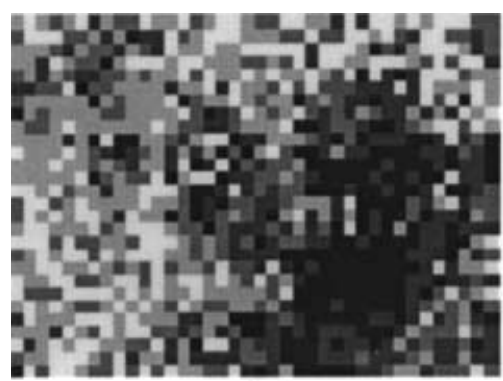

(a)

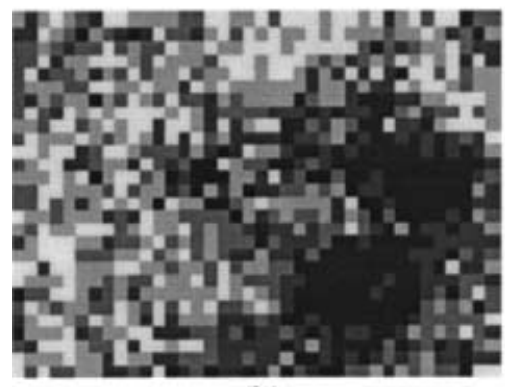

$8.0-11.8$

11.8-13.0

$13.0-15.5$

$15.5-18.6$

18.6-32

(b)

$(\mathrm{mg} / \mathrm{kg})$

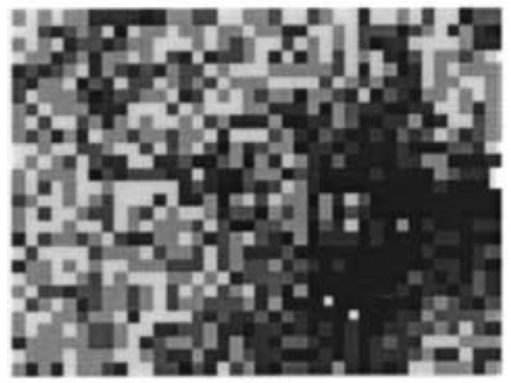

0

$0.6 \mathrm{~km}$
(C)

Fig. 9a-c

$\mathrm{Pb}$ simulated maps of a sas $1 ; \mathbf{b}$ sas2; $\mathbf{c}$ sas3 


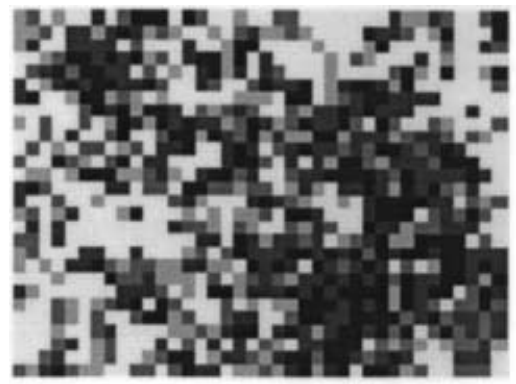

(a)

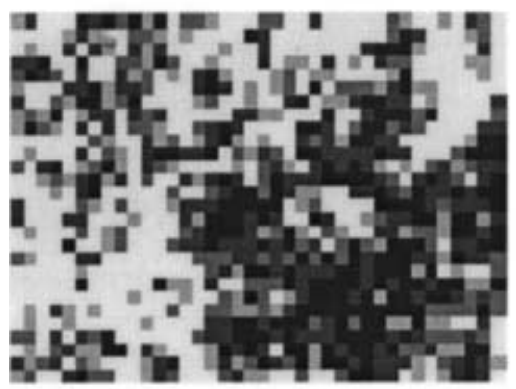

(b)

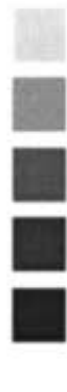

2.0-2.5

2.5-2.6

2.6-2.7

2.7-2.9

$2.9-4.0$

$\ln (\mathrm{mg} / \mathrm{kg})$

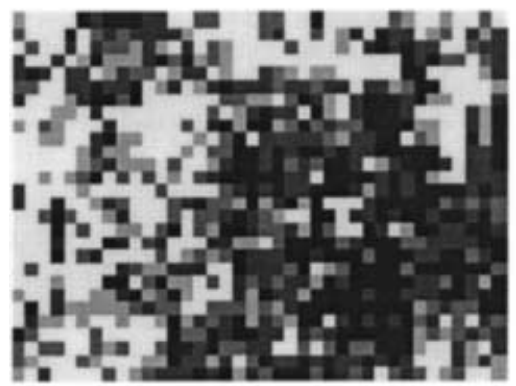

(c)

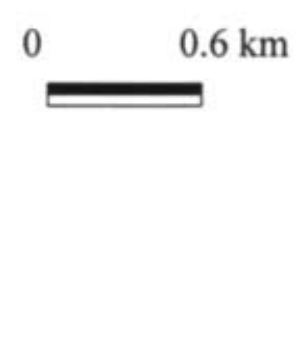

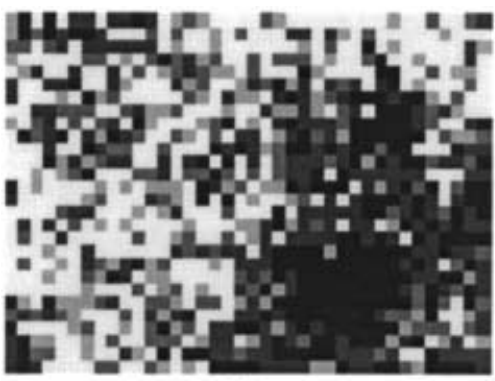

(a)

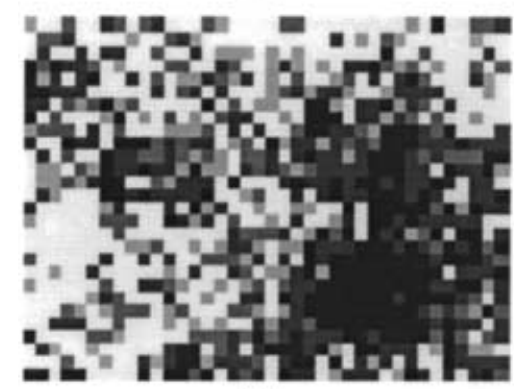

(b)

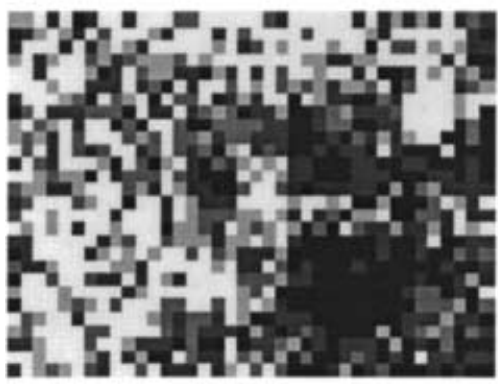

(C)

Fig. 11a-c

$\operatorname{Ln}(\mathrm{Pb})$ simulated maps of a sas 1 ; $\mathbf{b}$ sas2; c sas3

is almost identical to but slightly smaller than the shape in Fig. 12b.

\section{Conclusions}

This work has demonstrated the significant small-scale variations in measured $\mathrm{Pb}$ data within the area of interest. Although kriging and conditional simulation techniques, including Gaussian sequential simulation and simulated annealing, can both be used to identify pollution sources and patterns, ordinary kriging failed to reproduce the statistics of $\mathrm{Pb}$ and $\ln (\mathrm{Pb})$ better than simulation techniques. Meanwhile, in addition to reproducing the spatial variation of the measured $\mathrm{Pb}$ and $\ln (\mathrm{Pb})$, sequential Gaussian simulation and simulated annealing also identified global spatial continuity and discontinuity patterns. Moreover, when compared to global statistics and spatial patterns of $\mathrm{Pb}$ and $\ln (\mathrm{Pb})$ measurements, the simulated annealing method achieved more accurate results than sequential Gaussian simulation and kriging. Finally, the 


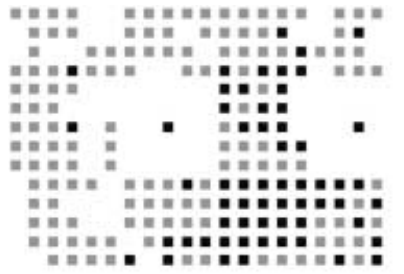

(a)

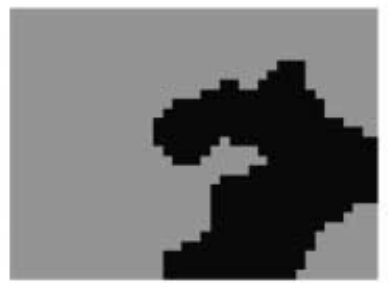

(b)

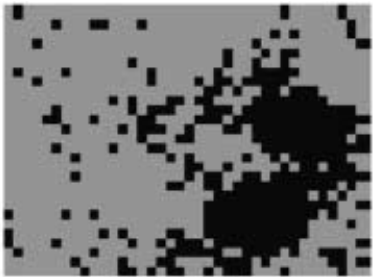

(c)

\section{Third Class}

Fourth Class

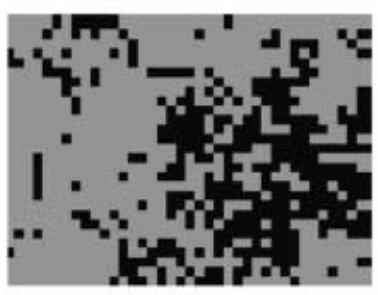

(d)

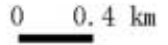
$4 \mathrm{~km}$

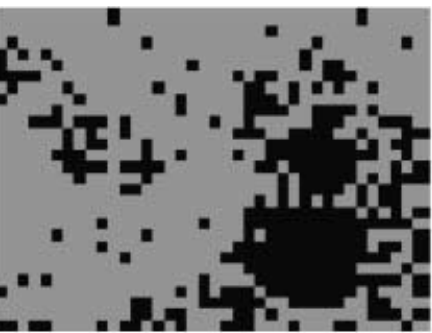

(c)

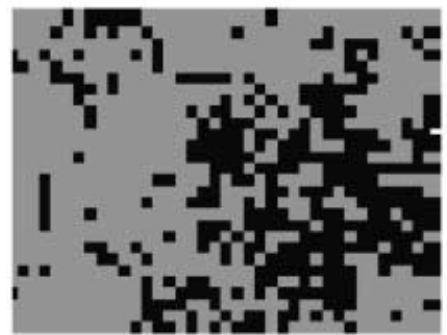

(d)

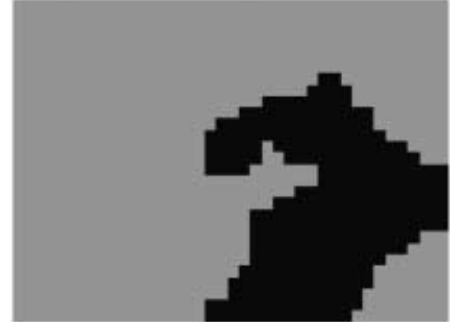

(b)

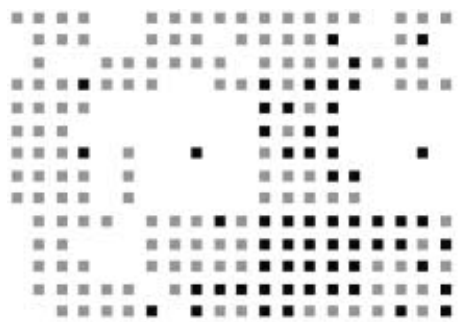

(a)

Fig. 13a-d

$\operatorname{Ln}(\mathrm{Pb})$ class spatial maps of $\mathbf{a}$ investigated data; $\mathbf{b}$ kriged; $\mathbf{c}$ simulated annealing; $\mathbf{d}$ sequential Gaussian simulation

realizations of sequential Gaussian simulation exhibited more local heterogeneity than those generated by simulated annealing. The realizations of simulated annealing simulation are consistent in presenting the spatial patterns of soil $\mathrm{Pb}$.

Acknowledgments The authors would like to thank the National Science Council of the Republic of China for financially supporting this research under Contract No. NSC87-2621-P-002012.

\section{References}

Chang TK, Shyu GS, Lin YP, Chang NC (1999) Geostatistical analysis of soil arsenic content in Taiwan. J Environ Sci Health A34(7):1485-1501
Fig. 12a-d

$\mathrm{Pb}$ class spatial maps of a investigated data; b kriged; c simulated annealing; $\mathbf{d}$ sequential Gaussian simulation

\section{Third Class}

\section{Fourth Class}

$0 \quad 0.4 \mathrm{~km}$

Christensen S (1997) On the strategy of estimating regional-scale transmissivity fields. Ground Water 35(1):131-139

Couto EG, Stein A, Klamt E (1997) Large area spatial variability of soil chemical properties in central Brazil agriculture. Ecosyst Environ 66(2):139-151

Cressie C (1990) The origins of kriging. Math Geol 22(2):239-252

Deutsch CV, Cockerham PW (1994) Practical considerations in the application of simulated annealing of stochastic simulation. Math Geol 26(1):67-82

Deutsch CV, Journel AG (1992) Geostatistical software library and user's guide. Oxford University Press, New York

Dowd PA (1982) Lognormal kriging - the general case. Math Geol 14(5):474-500

Eggleston JR, Rojstaczer SA, Peirce JJ (1996) Identification of hydraulic conductivity structure in sand and gravel aquifers: Cape Cod data set. Water Resour Res 32(5):1209-1222

ESRI (1998) Arcview 3.0. Environmental Systems Research Institute, Redlands, CA

Fabbri P (1997) Transmissivity in the geothermal Euganean basin: a geostatistical analysis. Ground Water 35(5):881-887 Fredericks AK, Newman, KB (1998) A comparison of the sequential Gaussian and Markov-Bayes simulation methods for small samples. Math Geol 30(8):1011-1032 
Gamma Design (1995) Gamma design software GS+. Geostatistics for the environmental sciences version 2.3. Gamma Design Software, Plainwell, MI

Goovaerts P (1996) Stochastic simulation of categorical variables using a classification algorithm and simulated annealing. Math Geol 28(7):909-921

Istok JD, Rautman CA (1996) Probabilistic assessment of groundwater contamination. 2. Results of case study. Ground Water 34(6):1051-1064

Journel AG (1980) The lognormal approach to predicting local distributions of selective mining unit grades. Math Geol 12(4):285-301

Juang KW, Lee DY (1998) A comparison of 3 kriging methods using auxiliary variables in heavy-metal contaminated soils. J Environ Qual 27:355-363

Keck TJ, Quimby WF, Nielson GA (1993) Spatial distribution of soil attributes on reconstructed mine soils. Soil Sci Am J 57:782756

Kentwell DJ, Bloom LM, Comber GA (1999) Improvements in grade tonnage curve prediction via sequential Gaussian fractal simulation. Math Geol 31(3):311-325

Lin YP, Chang TK (2000) Geostatistical simulation and estimation of the spatial variability of soil zinc. J Environ Sci Health A35(3):327-347

Litaor MI (1995) Spatial analysis of plutonium-239+240 and americium-241 in soils around Rocky Faults, Colorado. J Environ Qual 24:506-516

Mowrer HT (1997) Propagating uncertainty through spatial estimation processes for old-growth subalpine forests using sequential Gaussian simulation in GIS. Ecol Model 98:73-86

Rendu JM (1979) Normal and lognormal estimation. Math Geol 11(4):407-422

Rivoirard J (1990) A review of lognormal estimators for in situ reserves. Math Geol 22(2):213-221

Roth C (1998) Is lognormal kriging suitable for local estimation? Math Geol 30(8):999-1009
Rouhani S, Lin YP, Shi Y (1995) H-area/ITP geostatistical assessment in-situ and engineering properties. Final Tech Rep Westinghouse Savannah River Company, SC

Samra JS, Gill HS (1993) Modelling of variation in a sodiumcontaminated soil and associated tree growth. Soil Sci Soc Am J 52:1418-1423

Steiger BV, Webster R, Schulin R, Lehmann R (1996) Mapping heavy metals polluted soil by disjunctive kriging. Environ Pollut 94:205-215

Sterk G, Stein A (1997) Mapping wind-blown mass transport by modeling variability in space and time. Soil Sci Soc Am J 61:232-239

Varljen MD, Shafer JM (1991) Assessment of uncertainty in time related captures zones using conditional simulation of hydraulic conductivity. Ground Water 29:737-748

Wang XJ (1998) Kriging and heavy-metal pollution assessment in waste water irrigated agricultural soil of Beijing eastern farming regions. J Environ Sci Health A33(6):1057-1073

Wang XJ, Zhang ZP (1999) A comparison of conditional simulation, kriging and trend surface analysis for soil heavy metal pollution pattern analysis. J Environ Sci Health A34(1):73-89

White JG, Welch RM, Norvell WA (1997) Soil zinc map of the USA using geostatistics and geographic information systems. Soil Sci Soc Am J 61:185-194

Zhang R, Myers DE, Warrick AW (1992) Estimation of the spatial distribution for soil chemicals using pseudo-cross-variograms. Soil Sci Soc Am J 56:1444-1452

Zhang R, Rahman S, Vance GF, Munn LC (1995) Geostatistical analyses of trace elements in soils and plants. Soil Sci 159:383290

Zhang R, Shouse P, Yates S (1999) Estimates of soil nitrate distributions using cokriging with pseudo-crossvariogram. J Environ Qual 28:424-428 